\title{
Introduction to the Proceedings of ICTD2009
}

Welcome to the 3rd International Conference on Information and Communication Technologies and Development (ICTD2009). It is with great pleasure that we present the ICTD2009 proceedings, which include all of the full papers presented at the conference in Doha, Qatar, held on 17-19 April 2009.

ICTD is the premier series of scholarly conferences on the use of ICTs for development, spanning technical and social science domains. The call for papers attracted a record 250 submissions. All papers were put through a double-blind peerreview process. The Program Co-Chairs assigned papers to our Senior Program Committee members who oversaw a review process involving three Program Committee reviewers per paper: one with deep expertise about the subject matter; another with broad background in the area; and one drawn from an altogether different discipline. Our continuing hope is that this encourages a convergence of vocabulary and ideas within the ICTD field, while maintaining the integrity of different disciplines. The Senior Program Committee members then meta-reviewed the papers. Authors were allowed a brief rebuttal to reviewer comments before final acceptance decisions were made and revisions were finalized.

Ultimately, 19 papers were selected for oral presentation, and another 27 papers were chosen as full papers for poster presentation; an acceptance rate of just over $18 \%$. These papers represent some of the best work being done in ICTD today. They focus on a wide variety of development goals, and involve a broad and innovative range of digital technologies. They draw from all continents of the global South, and focus on all stages of the ICTD lifecycle: from readiness through design and adoption to use and impact. They also tell us about all levels, from the individual through communities and projects to ICTD programmes and policies. We hope that you will find them an insightful, provocative, and informative contribution to our fast-growing field of research and practice.

We wish to thank our keynote speakers William H. Gates, Chairman of Microsoft Corporation and Co-Chairman of the Bill and Melinda Gates Foundation, and Carlos A. Primo Braga, Director of the Economic Policy and Debt in the Poverty Reduction and Economic Management Network (PREM) at The World Bank for their insightful presentations. All the other conference presenters also deserve our gratitude for the variety of content and insights they added to the conference program.

We also need to thank a number of people without whom the program could not have been put together. First, we wish to thank our Honorary Chairs, Dr. Hessa Sultan AlJaber, Secretary General of The Supreme Council of Information and Communication Technology (ictQatar), and Dr. Kentaro Toyama, Assistant Managing Director of Microsoft Research India (MSRI) for their tremendous support in making this conference a success. We are of course deeply indebted to our Program Committee: those who did the hard work of reviewing and our senior PC members who managed the review process so effectively; all together it is they who ultimately steer the course of ICTD. We thank the Regional Chairs for their assistance in promoting the conference, and our Advisory Board which provided guidance and moral support; particularly Kentaro Toyama as the guiding light of ICTD. We also thank the Publication Chairs, Yonina Cooper and Thrishantha Nanayakkara, who made this 
proceedings possible; and Faheem Hussain and Tapan Parikh, who carried the load in organisation of the poster presentations.

The conference program for ICTD2009 went well beyond papers, and was significantly enhanced by demonstrations, organised by Bill Thies and Khaled Harras, and by a series of panels and workshops, organised by Joe Mertz and Joyojeet Pal. We are very grateful for their input and hard work.

This conference would not have been possible without the tireless efforts of a number of organizers and volunteers, notably our local organizing committee chairs Elaine Farah, Murry Evans, and Erin Stewart, and the many others on the local organizing committee, especially Dean Charles Thorpe, Sarah Belousov, Ermine Teves, Renee Barcelona, Kara Nesimiuk, Andy Zrimsek, Noha Al Afifi, Shams Hassan, Aaron Lyvers, Shamila Khader, Ray Corcoran, Bob Gaus, Freddie Dias, Daniel Freeman, and Jim Gartner. If there are others we did not name explicitly, it is our lapse.

The success of the conference is in part due to our many sponsors and partners. We are extremely grateful to our organizing partner, The Supreme Council of Information and Communication Technology (ictQatar), to our media partner Al Jazeera Children's Channel (JCC), to our technical sponsors IEEE and ACM, and to our financial sponsors, the Qatar National Research Fund (Platinum Sponsor); Canada's International Development Research Centre (Platinum Sponsor); Qatar Telecom (Platinum Sponsor); ExxonMobil (Gold Sponsor); Microsoft Corporation (Gold Sponsor); IBM (Bronze Sponsor); the Computer Science program at Carnegie Mellon University in Qatar (Bronze Sponsor); and other sponsors who asked not to be publicly acknowledged.

Finally, we are indebted to Carnegie Mellon University in Qatar for hosting the conference at their campus in Education City, and to the numerous employees of Carnegie Mellon University (in both the Pittsburgh and Doha campuses), especially the TechBridgeWorld team, who truly made this conference a success.

Thanks to everyone who contributed to ICTD2009 in so many ways, and thank you for participating! We are confident you will find the following papers, abstracts, and information not only interesting and useful, but the seeds for further research, innovation, and developmental impact.

$\begin{array}{ll}\text { Richard Heeks, University of Manchester } & \text { M. Bernardine Dias, Carnegie Mellon } \\ \text { Rahul Tongia, CSTEP, Bangalore } & \text { University } \\ \text { Program Chairs } & \text { Conference Chair }\end{array}$

